\title{
Overtopping Erosion and Failure Mechanism of Earthen Levee Strengthened by Vegetated HPTRM System
}

\author{
Yi Pan ${ }^{1}$, Lin $\mathrm{Li}^{2}$, Farshad Amini, ${ }^{2,}$ and Cuiping Kuang ${ }^{3}$ \\ ${ }^{1}$ College of Harbor, Coastal and Offshore Engineering, Hohai University, Nanjing, Jiangsu 210098, \\ China. \\ ${ }^{2}$ Department of Civil and Environmental Engineering, Jackson State University, Jackson, \\ Mississippi, 39217, USA \\ ${ }^{3}$ Department of Hydraulic Engineering, School of Civil Engineering, Tongji University, Shanghai, \\ 200092, China. \\ ${ }^{*}$ Corresponding author. Tel.: +1601 9793913; fax: +1601 9793238. Email address: \\ famini@jsums.edu (F. Amini)
}

\begin{abstract}
:
Prior studies have shown that the protection of landward-side slope of earthen levees against wave and surge overtopping during large storm surges is of great importance. In this research, a full scale flume test and erosion function apparatus tests were conducted to study the overtopping erosion and failure mechanism of landward-side slope of earthen levees strengthened by High Performance Turf Reinforcement Mat (HPTRM). An examination of soil loss from strengthened levee in the full-scale flume tests showed that overtopping flow velocity more correlated with soil erosion along the levee crest and landward-side slope than the shear stress. It is found that erosion starts near toe in the landward-side slope during combined wave and surge overtopping. The erodibilities of vegetated HPTRM system and grass were compared, and the result showed that the vegetated HPTRM system and grass increased the threshold on erosion. However, after the threshold velocity is reached, the vegetated HPTRM system performs much better on erosion resistance than the grass does. A conceptual model for soil loss from levee surface is presented to describe two erosion mechanisms of levee surface, erosion
\end{abstract}


starting position and the roles of the key hydraulic parameters (flow velocity/shear stress).

Keywords:

Embankments, Levees, Erosion, Failure, HPTRM

\section{Introduction}

Hurricane Katrina was one of the most devastating and deadliest disasters in U.S. natural disaster history with an estimated 1,300 human loss, 500,000 people having left the area, and 100 billion dollars of economic loss (ASCE Hurricane Katrina External Review Panel, 2007). The impact of hurricane Katrina was significantly increased by the fact that some levees failed. Post-Katrina investigations revealed that most earthen levee damage occurred on the levee crest and landward-side slope as a result of either wave overtopping, storm surge overflow, or a combination of both (e.g., ASCE Hurricane Katrina External Review Panel, 2007). The climate changes lead to the sea level rising at an increased rate and storms increasing in intensity and duration (IPCC, 2007), which increases the risk of combined wave and surge overtopping in the future. Hence,

protecting earthen levees from erosion by surge overflow and wave overtopping is absolutely necessary to assure a viable and safe levee system (Sills et al., 2008).

Analysis and field tests indicate that a large portion of the erosion failure occurs first on the landward-side slope of the overtopped levee and progressively regresses (Hanson et al., 2003; Hanson et al., 2005; Sills et al., 2008; van der Meer et al., 2009; Hughes and Nadal, 2009). However, concrete protection of the levees is repelled by the public for its inanimate and unnatural look. Vegetation linings are preferred by the public but they are weak in erosion resistance. The employment of a new lining system, High performance turf reinforcement mat (HPTRM), resolves this contradiction. HPTRM is a combination of nylon filaments matrix and polyester geogrid reinforcement at low strains to lock soil in 
place, and provides permanent reinforcement to prevent soil loss from the levee crest and landward-side slope during storm events (Pan et al., 2013; Yuan et al., 2014). HPTRM can raise the erosion resistance of the vegetation lining to a great degree, e.g., in some case TRM increases the permissible shear stress of vegetation lining from around $177 \mathrm{~Pa}$ to $672 \mathrm{~Pa}$, according to Nelsen (2005). The HPTRM mat and vegetated HPTRM system are illustrated in Fig. 1.

Although some studies have shown that the turf reinforcement mat increases the erosion resistance of vegetation (Hewlett et al., 1987; Chen and Cotton, 1988; Northcutt and McFalls, 1998; Lipscomb et al., 2003; Nelson, 2005), few studies have been conducted on the erosion resistance and failure mechanism of landward-side slope of HPTRM strengthened levees under combined wave and surge overtopping condition. The combined wave and surge overtopping conditions are the worst overtopping scenarios for the levee systems during Hurricane storm surges (Hughes and Nadal 2009).

Many studies have been conducted on the erosion and failure process of the earthen dam and levees (e.g., Johnson and Illes, 1976; Singh and Snorrason, 1982; MacDonald and Langridge-Monopolis, 1984; Ralston, 1987; Powledge et al., 1989; Singh, 1996; Hahn et al., 2000; Oumeraci et al., 2005; Geisenhainer and Kortenhaus, 2006; Doorn, 2007; Zech and Soares-Frazão, 2007; Piontkowitz, 2009). However, among these studies on two issues there were no well-accepted conclusions. The first issue is the position of erosion starting spot. Some observations show that a notch at the top of the dam is first triggered in the erosion process (e.g., Johnson and Illes, 1976; MacDonald and Langridge-Monopolis, 1984). Other studies show that small headcut is typically formed near the toe of the dam and then advances upstream until the crest of the dam is breached (e.g., Ralston, 1987; Powledge et al., 1989). Embankment experiments indicate that rills are initiated on the slope first and then rills lead to the headcut (e.g., Hahn et al., 2000). The second issue is the choice of the hydraulic parameter that is used 
to evaluate the erodibility of the dam/levee. Erodibility is a term often used in scour and erosion studies. Erodibility can be defined as the relationship between the velocity/shear stress of the water flowing over the soil and the corresponding erosion rate experienced by the soil (Briaud et al., 2008). Usually a critical flow velocity or a critical shear stress is defined as the threshold of soil erosion. After the threshold is reached, the soil is eroded at an erosion rate that is of concern by researchers and engineers. The properties of the soil (e.g., erosion rate, plasticity, unit weight, shear strength, compaction) have been shown to have impacts on the erodibility of the soil (Dodge, 1988; Chen and Cotton, 1988; Fread, 1988; Hanson et al., 2003), while for the hydraulic parameters, usually both flow velocity and shear stress have been used in the evaluation of the erodibility, but few discussions have been given on the choice of the two hydraulic parameters.

In this study, the overtopping erosion on the HPTRM-strengthened earthen levees on the crest and landward-side slope was studied. Full-scale flume tests and Erosion Function Apparatus (EFA) tests were conducted to study the erosion resistance performance of vegetated HPTRM system. As pointed out by many researchers (e.g., Kilgore and Cotton 2005; Hughes 2008), it is difficult to model the erosion process of levee numerically or in small-scale physical models, and the roughness of strengthening systems must be determined by full-scale testing in laboratory flumes using defined testing protocols. Therefore, in this study, the flume tests were conducted in full-scale conditions. In the full-scale flume tests, the HPTRM-strengthened levee was tested against combined wave and surge overtopping (Fig. 2). During the flume tests, hydraulic parameters and soil erosion of the vegetated HPTRM system were recorded. After the full-scale flume tests, samples of grass-covered clay (without HPTRM) and naked clay were collected and tested to study the soil erodibilities using EFA testing method (Briaud et al., 2001). The samples were taken from the tested HPTRM system after the HPTRM mat was removed. The EFA results were placed on the erodibility classification chart of flow velocities and the erodibility classification chart of shear stresses. A conceptual 
model for soil loss from levee surface is provided to describe two erosion mechanisms of levee surface, the erosion starting position and the key hydraulic parameter (flow velocity/shear stress).

\section{Description of laboratory experiments}

The full-scale flume tests were conducted in the Large Wave Flume at Oregon State University (Pan et al., 2013, Yuan et al., 2014) with the same testing protocol and HPTRM system. After the flume tests, soil samples were collected for EFA tests.

\subsection{Full-scale flume tests under combined wave and surge overtopping}

The dimension of the wave flume and the levee embankment is shown in Fig. 3. The vegetated HPTRM system was built into a steel tray, which was placed in the test section before the tests began. The property of the grass was a warm-season southern Bermuda grass. Based on the capability of the piston wave maker, 9 combined wave and surge cases with different conditions were tested. During all the tests, irregular random wave time series realization was generated conforming to the idealized TMA spectrum, and flow velocities and flow depths at P1 to P5 were measured at a $50 \mathrm{~Hz}$ rate with Acoustic Doppler Velocimeters (ADV) and Acoustic Range Finders (ARF), respectively. At each point, a down-looking ADV sensor and a side-looking ADV sensor were placed. The down-looking ADV sensors measure the flow velocity about $5 \mathrm{~cm}$ above the grass, and the side-looking ADV sensors measure the flow velocity about $2 \mathrm{~cm}$ above the grass. However, it should be mentioned that the ADV sensor must be submerged during working. Thus, when the flow depth is smaller than $10 \mathrm{~cm}$, the measurement of the down-looking ADV sensors is meaningless. At the locations lower than P5, the flow field is disordered because of aerated flow, broken waves, and high velocity, so no sensor was placed. After 
each test, soil surface elevations were measured at 64 positions on the crest and the landward-side slope. The average values of the eight measurement points around P1 to P5 were taken as the soil loss at each point. Additional details about the flume tests can be found in Pan et al. (2013).

\subsection{EFA tests}

After completion of the full-scale flume tests, the vegetated HPTRM system was sampled and tested using EFA (Briaud et al., 2001) testing method. After the full-scale flume tests in November 2009 (phase 1), three soil samples were taken from the vegetated HPTRM system, namely $\mathrm{O} 1$ to O3. After the full-scale flume tests in September 2011 (phase 2), eight soil samples were taken from the vegetated HPTRM system, namely $A 1$ to $A 4$ and $B 1$ to $B 4$. The samples were $152.4 \mathrm{~mm}$ in length and $76.2 \mathrm{~mm}$ in diameter. The locations of the sampling points are shown in Fig. 4. Before soil samples were taken, the HPTRM mat was removed because it is hard to conduct EFA tests with HPTRM mat on the samples.

As shown in Fig. 5, the EFA test consists of eroding a soil sample by pushing it out of a thin wall steel tube and recording the erosion rate for a given velocity of the water flowing over it (Briaud et al., 2001). Each tested velocity was maintained for approximately 45 minutes after which the soil erosion was measured. The samples have two sides, one with grass and the other with clay only. For each soil sample, both sides were tested and the results represent the performances of grass and naked clay respectively. During the EFA tests of both sides, $1 \mathrm{~mm}$ of soil is maintained out of the steel tub, as shown in Fig. 5. For some of the samples, one of the sides was in poor condition before the EFA tests began and thus only the other side was tested. The measured erosion rates versus given velocities and corresponding shear stresses were plotted on the erodibility classification charts, as in Fig. 6. 
It should be mentioned that samples taken from untested HPTRM system were more representative than those taken from the tested HPTRM system. Untested HPTRM samples would also avoid the different initial erosion conditions due to different sampling positions. However, after completion of all the tests, no failure was observed, and the soil erosion was limited and ranged from 3 to $11 \mathrm{~mm}$. Thus, it is considered that after the flume tests have been completed, the HPTRM system was under slight erosion and there was little difference between tested and the untested HPTRM system. In addition, as illustrated later, the performance of clay-side and grass-side are different from each other. Thus, the key factor that affects the erosion function is the type of surface lining. Hence, the discussions and conclusions based on the results of tested HPTRM system are reasonable.

\subsection{Initial data processing}

Flow velocity and shear stress are the two hydraulic parameters that relate to soil erosion. The studies on the permissible values of the two parameters on grass or TRM were conducted by several researchers (e.g., Chow, 1959; Chen and Cotton, 1988; Nelsen, 2005). In this study, both flow velocity and shear stress were calculated to investigate the feature of erosion process.

Average flow velocity was chosen for the analysis of erosion. In the flume tests, average overtopping velocities of combined wave and surge overtopping, $v_{w s}$, was calculated by dividing average overtopping discharge by the average flow thickness at P1, P3 and P4 for each test. The average overtopping discharges were calculated with the measurements of two ADV sensors and one ARF sensor at P1. The average flow thickness at P1, P3 and P4 were calculated with the measurements of the ARF sensors at each point. In the EFA tests, the profile-averaged flow velocity calculated by the flow discharge was taken as the average flow velocity used in the study. The reason for 
choosing average flow velocity is that it is relatively easy to calculate and it reflects the effect of the total flow discharge.

Due to different flow structures, shear stresses in flume tests and EFA tests were calculated using different methods. In the flume tests under combined wave and surge overtopping conditions, the flow comes with not only high instantaneous velocities but also sharp changes in flow velocity and flow depth. Hence, unlike the conditions of steady flow or piping (e.g., Kakuturu and Reddi, 2006a; Kakuturu and Reddi, 2006b), the calculation of shear stress under combined wave and surge overtopping condition should involve not only the flow velocity but also the change of flow. In this paper, the time series of shear stress at 3 measuring points (P1, P3 and P4) were calculated using the momentum equation of Saint-Venant equations (Sturm, 2001; Nadal and Hughes, 2009) given by

$$
\frac{\partial v}{\partial t}+v \frac{\partial v}{\partial s}+g \frac{\partial h}{\partial s}+g S_{f}-g \sin \theta=0
$$

and

$$
\tau_{0}=\gamma_{w} h S_{f}
$$

where $v$ is the flow velocity parallel to the slope, $t$ is the time, $s$ is the down-slope coordinate, $g$ is acceleration of gravity, $h$ is the flow thickness perpendicular to the slope, $S_{f}$ is the friction slope, $\theta$ is the angle of levee slope to horizontal, $\tau_{0}$ is the shear stress, $\gamma_{w}$ is the specific weight of water. As can be seen from Eq. (1), the shear stress is controlled by values of $v, h, \partial v / \partial t, \partial v / \partial s$, and $\partial h / \partial s$. That is to say, the impact force caused by the sudden increase of flow velocity and flow depth during wave overtopping is considered herein. The time series of shear stress at P1, P3 and P4 were calculated using the time series of flow depth and flow velocity measured at each point. Wave front velocities on the levee slope estimated by Pan et al. (2013) were used in the determination of the changes in flow depth and flow velocity along the down-slope for the 
calculation of the partial derivatives of flow thicknesses and velocities.

The shear stresses were estimated using Moody chart (Moody, 1944), which has been proved to be an appropriate method to calculate the shear stress for EFA tests in (Briaud et al.; 2001). In Moody chart, the friction factor, $f$, can be calculated with

$$
\frac{1}{\sqrt{f}}=-2 \cdot \log \left(\frac{\varepsilon / D}{3.7}+\frac{2.51}{R_{e} \sqrt{f}}\right)
$$

where $\varepsilon / D$ is the pipe roughness, $R e$ is the Reynolds number, log is the operator of logarithm of 10 . With the value of friction factor, the shear stress, $\tau$, can be calculated with

$$
\tau=\frac{1}{8} \rho f v^{2}
$$

Where $\rho$ is the mass density of water $\left(1,000 \mathrm{~kg} / \mathrm{m}^{3}\right), v$ is the mean flow velocity in the pipe. More detail about the calculation of shear stress in EFA tests can be found in Briaud et al. (2001).

\section{Results and discussion}

\subsection{Soil erodibility}

The EFA test results of the samples are shown in the erodibility classification charts of velocities and shear stresses in Fig. 6. The EFA test results of the clay-sides of the samples are plotted in hollow symbols, while the EFA test results of grass-sides of the samples are plotted in solid symbols. As shown in both the erodibility classification charts of velocities and shear stresses, the clay-sides of the samples mainly fall in Category II (high erodibility), while the grass-sides of the samples mainly fall in Category III (medium 
erodibility). However, for some of the samples, the classification chart of velocities and the classification chart of shear stresses result in different classifications. Most of the data points of clay side of $\mathrm{O} 1$ and grass side of $\mathrm{B} 1$ fall into medium erodibility category in erodibility classification chart of shear stresses, but into low erodibility category in erodibility classification chart of velocities. It can also be noted that some differences exist on the distribution and relative positions of the data points in the erodibility classification charts of velocities and shear stresses.

It is well known that for an open-channel flow, the shear stress can be calculated with the flow velocity profile (e.g., Gudavalli et al., 1997). However, in the case of combined wave and surge overtopping, the flow velocity keeps changing, and thus the average overtopping velocities, Kws, is used to evaluate the erodibility. In addition, the shear stress is influenced not only by the flow velocity but also by the change in flow velocity and flow depth. Hence, the distributions of flow velocity and shear stress are not the same. Hence, the question is, in the case of wave overtopping and landward-side slope erosion, which one is the key factor, shear stress or flow velocity, that controls the soil loss, or which one should be used in the evaluation of the soil erodibility?

\subsection{Soil loss in full-scale flume tests}

The total soil loss measured after each overtopping test is shown in Fig. 7. Soil loss increases as measurement location gets lower along the landward-side slope, which indicates that more erosion occurs at downstream position on the landward-side slope. Erosion starts at low position along the landward-side slope (e.g., near the toe of the HPTRM strengthened levees) during wave and surge overtopping.

Fig. 7 indicates that after a certain test (trial 4 for $\mathrm{P} 1$ and $\mathrm{P} 2$, trial 5 for $\mathrm{P} 3$ and $\mathrm{P} 4$ ), the soil losses from P1 to P4 did not increase obviously; the soil losses at P5 kept increasing, but the increase was relatively small after trial 6 . It seems the erosion reached an "upper 
limit" after which the erosion stopped to increase under similar flow condition. This observation of "upper limit" can be explained by the fact that after the exposing of HPTRM mat and the increase in the "anti-erosion" capability, a balance is reached between the agents of erosion and the "anti-erosion" capability as discussed by Pan et al. (2013) and Li et al. (2014). To determine whether flow velocity or shear stress should be adapted in the evaluation of the erodibility in HPTRM strengthened levee, the average shear stresses and average overtopping flow velocities at P1, P3, P4 and P5 were plotted in Fig. 8. Since an "upper limit" exists for erosion, only the data before reaching the "upper limit" for each point is plotted. As shown, the correlation between the shear stress and the erosion rate is not clear while a relationship can be found between the flow velocity and the erosion rate. A threshold velocity, after which erosion starts to occur, is noted. The values of the threshold velocities range from 1.5 to $2.0 \mathrm{~m} / \mathrm{s}$ for different points. After the threshold velocity is reached, the relation between erosion rate and average flow velocity is approximately linear. Therefore, it is concluded that compared to the shear stress, the flow velocity is better correlated to the soil erosion along the levee crest and landward-side slope in vegetated HPTRM system case. It should be mentioned that the use of the threshold velocity should be limited to the overtopping condition and the linear relationship should be limited to the tested range.

\subsection{Erosion resistance of the vegetated HPTRM system and grass}

Fig. 9 shows the erosion resistance of vegetated HPTRM system and grass using data from EFA tests and flume tests. As shown, threshold velocities, after which the erosion starts to happen, exist for naked clay, grass lining and vegetated HPTRM system. After the threshold velocities are reached, the erosion rates increase with flow velocities. The threshold velocity for naked clay is in the order of $0.5 \mathrm{~m} / \mathrm{s}$, while the threshold velocity for both grass-covered clay and vegetated HPTRM system is in the order of 1.5 
$\mathrm{m} / \mathrm{s}$. Both the grass and vegetated HPTRM system cause the threshold velocity to increase by around $1 \mathrm{~m} / \mathrm{s}$. It is noted that the distribution of the threshold velocities is relatively scattered, with the lowest threshold velocity being close to that of the naked clay samples. The scattered distribution could be explained by the differences in the condition of the grass cover on the samples, as shown in Fig. 10. Different initial erosion condition of soil before sampling would also be one of the reasons for the scattered distribution.

After the threshold velocity is reached, the erosion rates increase very sharply with the continuous increase in flow velocities for both naked clay and grass-covered clay samples. It should be noted that the vegetated HPTRM system in the full-scale flume tests are tested under unsteady flow induced by combined wave and surge overtopping, while in the EFA tests, the samples are tested under steady flow with constant velocity. Thus, the direct comparison of soil erodibility between full-scale flume tests and EFA tests should be avoided. However, similar erosion processes of vegetated HPTRM system and grass lining could be found: erosion occurs when flow velocity reaches a threshold velocity, after which the erosion rate increases with the flow velocity. Under the condition of combined wave and surge overtopping in the flume tests, the erosion rate also increases sharply after the threshold velocity is reached, but the erosion rate (at most 4 $\mathrm{mm} / \mathrm{hr}$ ) is acceptable in the tested range of hydraulic condition. This means that after the threshold velocity is reached, the grass lining may fail quickly, while the vegetated HPTRM system would still play a protective role. When the top layer of the clay is eroded from the vegetated HPTRM system, the newly-exposed clay is protected by the entire vegetated HPTRM system, as shown in Fig. 11. In other words, the vegetated HPTRM system would not increase the threshold velocity obviously, but it provides a persistent strength of the levee surface after the threshold velocity is reached.

\subsection{Conceptual model of soil loss from levee surface}


Two issues exist in the domain of the erosion and failure process of the earthen dam and levees. The first issue is the position of erosion starting spot. According to existing studies, the erosion starting spot could be top of the dam (e.g., Johnson and Illes, 1976; MacDonald and Langridge-Monopolis, 1984), landward-side slope (e.g., Hahn et al., 2000) or toe of the dam (e.g., Ralston, 1987; Powledge et al., 1989). The second issue is the choice of the hydraulic parameter that is used to evaluate the erodibility of the dam/levee. Usually both flow velocity and shear stress have been used in the evaluation of the erodibility, but few discussions have been given on the choice of the two hydraulic parameters. In the case of combined wave and surge overtopping, the distributions of flow velocity and shear stress are not the same. Therefore, in the evaluation of the soil erosion under the unsteady overtopping flow, one needs to know which one is more related to the soil erosion. To answer the two questions for the erosion of HPTRM-armored levees under overtopping flow, a conceptual model for soil loss from levee surface was developed.

It is assumed that two types of levee erosion mechanisms, i.e., particle erosion and block erosion, correspond to the levee erosion on crest and landward-side slope. Particle erosion and block erosion are related to two hydraulic facts, microscopic shear force and macroscopic shear force, respectively. The microscopic shear force, indicating the sediment carrying force acting on single particles, is directly related to the flow velocity. The macroscopic shear force, indicating the wave/flow action on the levee surface, is induced by the act of the wave and the change in flow velocity. The particle erosion is induced by the microscopic shear force. In the process of particle erosion (Fig. 12(a)), soil particles are taken away from the levee surface one by one due to high flow velocity. As a result, particle erosion increases gradually and smoothly, and the degree of erosion is directly affected by the microscopic shear force, the weight of particle and the forces among particles. After adequate particles have left the surface, a rill occurs on the levee 
surface. The block erosion is induced by macroscopic shear force. In the process of block erosion (Fig. 12(b)), when the macroscopic shear stress reaches the shear strength of the weakest structural surface near the levee surface, a small block of soil is taken away from the levee surface and erosion starts to occur. As the shear stress increases and the exposure of new weak structure surface happens, the levee surface is destroyed at the weak structure surfaces and soil is taken away from levee surface block by block. If shear stress keeps increasing, huge amount of soil would be taken away and breach happens. Therefore, block erosion occurs at the maximum shear stress in a relatively short process.

Based on the hypothesis of the two different erosion mechanisms, the observations that the erosion is triggered at different locations of the dam/embankment can be explained. In an overtopping case, both types of erosion might happen. The failure of the levee caused by the particle erosion could be defined by a certain erosion depth, which is large enough to form a rill on the levee surface; and the failure of the levee caused by block erosion could be defined by a threshold shear stress which causes the weakest structure surfaces start to be destroyed. Different types of levee/embankment have different erodibilities against microscopic shear force and different macroscopic shear strengths, therefore, different erosion starting spot can be observed in different cases.

The macroscopic shear stress can be calculated with Saint-Venant equations (Sturm, 2001; Nadal and Hughes, 2009) or the velocity profile (Gudavalli et al., 1997), and also it is easy to test the shear strength (threshold shear stress) of the levee surface material. Hence, one can predict the occurrence of the block erosion. In the scale of the diameter of clay particle, it is difficult to estimate the shear force acting on a single particle accurately; and because of the electromagnetic and electrostatic forces between particles, it is not easy to estimate the resistance against particle leaving. However, since the microscopic shear force is related to the flow velocity, and since the erodibility of a given material against flow velocity can easily be tested, the particle erosion is also predictable. 
With the hypothesis of the two different erosion mechanisms, it is easy to explain the erosion distribution along the levee slope and the key hydraulic parameter related to erosion in the flume tests. In HPTRM overtopping case, the shear strength of levee surface was enhanced largely by HPTRM (Sprague, 1999; Pan et al., 2013; Yuan et al., 2014), and as a result, the particle erosion happened first. This mechanism is the reason why in HPTRM-strengthened case, the erosion is related to the flow velocity rather than the shear stress. And because the particle erosion is more related to flow velocity, the erosion gets larger in lower position with large average flow velocity. It should be noted that because of the protective effect of HPTRM discussed earlier, the flow velocity-induced erosion stopped when the "upper limit" of soil loss is reached. It may also be noted that this conceptual model is only concerned with the position of the initial erosion and not the processes of the development of erosion after a rill or headcut has been formed.

Since the hypothesis of the two types of erosion mechanisms explains the flume test data and EFA test data well, and answers the shear stress or flow velocity question and the erosion starting point question, it is considered that the hypothesis is reasonable. However, due to limited sample size, the conceptual model is qualitative and given tentatively, and additional test data is needed to obtain more quantitative conclusions.

\subsection{Failure modes of HPTRM-strengthened levee}

Because HPTRM raises the erosion resistance of the vegetation lining, it is difficult to model the failure process of vegetated HPTRM system in the lab. In this paper the failure process of the vegetated HPTRM system is given tentatively based on the conceptual model.

For the HPTRM-strengthened levee, the HPTRM mat prevents the block erosion by subjecting most of the macroscopic shear stress and restricting the movement of soil 
blocks. Therefore, the failure induced by macroscopic shear stress can only be caused by the destruction of the HPTRM mat itself or the tearing off of the HPTRM mat from the levee surface. Noticing that the strength (Ultimate tensile strength $=30 \mathrm{kN} / \mathrm{m}$ ) of the HPTRM mat is much higher than the adhesion strength between the HPTRM mat and the levee surface, the mode of the failure induced by the macroscopic shear stress is the tearing off of the HPTRM mat from the levee surface, as shown in Fig. 13(a). When the water flow is fast enough, the transient shear stress induced by a large wave may exceed the adhesion strength between the HPTRM mat and the levee surface at one weak position, leading to the tearing off the HPTRM mat, and then failure happens. If the water flow is not able to tear the HPTRM mat off from the levee surface in a short time, the HPTRM-strengthened levee would suffer from continuous particle erosion and may also eventually fail. In this case, the occurrence of failure requires two conditions: flow intensity and duration. First, the water flow should be powerful enough so that the "upper limit" of soil erosion is higher than the thickness of the HPTRM mat. Second, the overtopping duration needs to be long enough to allow the erosion to develop to the bottom of the HPTRM mat, as shown in Fig. 13(b). Without the adhesion force between the HPTRM mat and the levee surface, the HPTRM mat would easily be torn off and then failure happens. However, in an overtopping case in which the water flow is not able to tear the HPTRM mat off at first (the same as the beginning case (b) shown by Fig. 13), the failure might not wait until the erosion develops to the bottom of the HPTRM mat to happen. That is because the adhesion strength between the HPTRM mat and the levee surface would keep decreasing in the process of the development of the particle erosion due to the thinning of the soil in the HPTRM mat. When the adhesion strength reaches the transient shear stress induced by the largest waves, the HPTRM mat is torn off and failure happens, as shown in Fig. 13(c). It is noted that the adhesion strength is usually large, and hence the combined wave and surge overtopping cases which produce much larger instantaneous shear stress is more dangerous than steady surge-only overflow 
cases.

\section{Conclusions}

In this paper, the anti-erosion performance of vegetated HPTRM system and failure mechanism of HPTRM-strengthened levee against combined wave and surge overtopping conditions is investigated via full-scale flume tests and EFA tests. Before the discussion on the erosion resistance and failure mechanism of HPTRM-strengthened levees, two questions were raised: a) shear stress or flow velocity, which one should be adapted in the evaluation of the erodibility, and b) where is the position of erosion starting point along the landward-side slope during the wave and surge overtopping?

From analysis of the flume test results, the flow velocity is more correlated with the soil erosion in the distribution along the levee crest and landward-side slope for the HPTRM-strengthened levee, and erosion starts at low position along the landward-side slope (e.g., near the toe of the levee) during wave and surge overtopping.

Using flow velocity as the key parameter, comparisons of the anti-erosion performances are performed among the naked clay, clay with grass and vegetated HPTRM system. It is concluded that both the grass and vegetated HPTRM system can increase the threshold velocity by $1 \mathrm{~m} / \mathrm{s}$ compared to the naked clay, however, after the threshold velocity is reached, the grass cover may fail quickly while the vegetated HPTRM system would still play a protective role. The similarities and differences of the characteristics of the erosion resistance between the HPTRM system and grass can be explained by the fact that the top layer of the vegetated HPTRM system is protected by the grass rather than the HPTRM mat, while after the top layer of the clay is eroded, the newly-exposed clay is protected by the entire vegetated HPTRM system.

A conceptual model was developed to define two types of levee surface erosion, particle erosion and block erosion. The particle erosion is induced by the sediment 
carrying force acting on single particles and thus is related to the flow velocity; the block erosion is induced by the wave/flow action acting on the levee surface and is related to the shear stress. Different types of levee surfaces have different anti-erosion capabilities to resist the two types of levee surface erosion, and hence flow velocity and shear stress are both suitable in different cases. This is also the reason why erosion starts in different positions in different cases. The failure of HPTRM-strengthened levee may be induced by the tearing off the HPTRM mat or long-time particle erosion, or a combination of the two. The occurrence conditions of the failure induced by each mechanism are provided.

\section{List of Symbols}

$R_{c} \quad$ freeboard of the levee, i.e., the vertical distance between the still water elevation and crest elevation [m]

$T_{p} \quad$ peak spectral wave period [s]

$H_{s} \quad$ significant wave height [m]

$H_{m o} \quad$ energy-based significant wave height [m]

$q_{w s} \quad$ average overtopping discharge of combined wave and surge overtopping per unit length $\left[\mathrm{m}^{3} / \mathrm{s} / \mathrm{m}\right]$

$m \quad$ water-side slope

\section{Acknowledgements}

The full-scale tests were funded by the Department of Homeland Security-sponsored Southeast Region Research Initiative (SERRI) at the Department of Energy's Oak Ridge National Laboratory. The full-scale tests were conducted at the O. H. Hinsdale Wave Research Laboratory at Oregon State University. The first author wants to thank the Natural Science Fund for Colleges and Universities in Jiangsu Province (BK20130833), the National Natural Science Foundation of China (51309092), and the Fundamental Research Funds for the Central Universities (2013B03414). Thanks are also expressed to 3 anonymous reviewers for their works. The reviewers' comments are very helpful to improve this manuscript. 


\section{References}

ASCE Hurricane Katrina External Review Panel, 2007. The New Orleans Hurricane Protection System: What Went Wrong and Why? Reston, Virginia: American Society of Civil Engineers, 92p.

Briaud, J.L.; Ting, F.; Chen, H.C.; Cao, Y.; Han, S.W., and Kwak, K., 2001. Erosion Function Apparatus for Scour Rate Predictions. Journal of Geotechnical and Geoenvironmental Engineering, 127(2), 105-113.

Briaud, J.L.; Chen, H.C.; Govindasamy, A.V., and Storesund, R., 2008. Levee erosion by overtopping in New Orleans during the Katrina Hurricane. Journal of Geotechnical and Geoenvironmental Engineering, 134(5), 618-632.

Chen, Y.H. and Cotton, G.K., 1988. Design of Roadside Channels with Flexible Linings. Hydraulic Engineering Circular 15. U.S. Department of Transportation, Federal Highway Administration.

Chow, V.T., 1959. Open Channel Hydraulics. New York: McGraw-Hill.

Dodge, R.A. 1988. Overtopping flow on low embankment dams - Summary report of model tests. Rep. No. REC-ERC-88-3, U.S. Bureau of Reclamation, Denver.

Doorn, N., 2007. Understanding and predicting failure modes - Activity 4.1: Failure modes for revetments. FLOODsite Project Report.

Fread, D.L., 1988. BREACH: An erosion model for earthen dam failures. National Weather Service, National Oceanic and Atmospheric Administration, Silver Spring, Md.

Geisenhainer, P. and Kortenhaus, A., 2006. Hydraulic model tests on breaching with and without waves: description of experiments performed at LWI. FLOODsite Project Report. Report Number T06-06-02. http://www.floodsite.net/html/ partner_area/search_results3b.asp?doclD =44 
Gudavalli, R.; Ting, F.C.K.; Briaud, J.L.; Chen, H.C. Perugu, S., and Wei, G., 1997. Flume tests to study scour rate of cohesive sails. Research Report Prepared for Texas Department of Transportation, Department of Civil Engineering, Texas A\&M University, College Station, Tex.

Hahn, W.; Hanson, G.J., and Cook, K.R., 2000. Breach morphology observations of embankment overtopping tests. In: Proceedings of the 2000 Joint Conference on Water Resources Engineering and Water Resources Planning and Management (Minneapolis, Minnesota, ASCE), pp. 1-10.

Hanson, G.J.; Cook, K.R.; Hahn, W., and Britton, S.L., 2003. Observed erosion processes during embankment overtopping tests. In: American Society of Agricultural Engineers Annual International Meeting (Las Vegas), Paper 032066.

Hanson, G.J.; Cook, K.R., and Hunt, S.L., 2005. Physical modeling of overtopping erosion and breach formation of cohesive embankments. Transactions of the ASABE, 48(5), 1783-1794.

Hewlett, H.M.; Boorman, L.A., and Bramley, M.E., 1987. Guide to the Design of Reinforced Grass Waterways. CIRIA Report 116. London: CIRIA.

Hughes, S.A., 2008. Levee overtopping design guidance: what we know and what we need. In: Proceedings of the Solutions to Coastal Disasters Congress (Turtle Bay, Oahu, Hawaii, ASCE), pp. 867-880.

Hughes, S.A. and Nadal, N.C., 2009. Laboratory study of combined wave overtopping and storm surge overflow of a levee. Coastal Engineering, 56(3), 244-259.

IPCC (International Panel on Climate Change), 2007. Climate change 2007: The physical science basis. In: Solomon, S.; Qin, D.; Manning, M.; Chen, Z.; Marquis, M.; Averyt, K.B.; Tignor, M., and Miller, H.L. (eds.), Contribution of Working Group I to the Fourth Assessment Report of the Intergovernmental Panel on Climate Change. Cambridge, United Kingdom: Cambridge University Press.

Johnson, F.A. and Illes, P., 1976. A classification of dam failures. International Water 
Power \& Dam Construction, 28(12), 43-45.

Kakuturu, S. and Reddi, L.N., 2006a. Evaluation of the parameters influencing self-healing in earth dams. Journal of geotechnical and geoenvironmental engineering, 132(7), 879-889.

Kakuturu, S. and Reddi, L.N., 2006b. Mechanistic model for self-healing of core cracks in earth dams. Journal of geotechnical and geoenvironmental engineering, 132(7), 890-901.

Kilgore, R.T. and Cotton, G.K., 2005. Design of Roadside Channels with Flexible Linings Hydraulic Engineering Circular Number 15, Third Edition. Report No. FHWA-NHI-05-114. Federal Highway Administration, National Highway Institute.

Li, L.; Amini, F.; Pan, Y.; Kuang, C.P., and Briaud, J.L., 2014. Erosion Resistance of HPTRM Strengthened Levee from Combined Wave and Surge Overtopping. Journal of Geotechnical and Geological Engineering, 32(4), 847-857.

Lipscomb, C.M.; Theisen, M.; Thornton, C.I., and Abt, S.R., 2003. Performance testing of vegetated systems and engineered vegetated systems. Proceedings of the International Erosion Control Association Conference, 34, 1-13.

MacDonald, T.C. and Langridge-Monopolis, J., 1984. Breaching characteristics of dam failures. Journal of Hydraulic Engineering, 110(5), 567-586.

Moody, L.F., 1944. Friction factors for pipe flow. Transactions of the American Society of Mechanical Engineers, 66.

Nadal, N.C. and Hughes, S.A., 2009. Shear Stress Estimates for Combined Wave and Surge Overtopping at Earthen Levees. Coastal and Hydraulics Engineering Technical Note ERDC/CHL CHETN-III-79. Vicksburg, Mississippi: U.S. Army Engineer Research and Development Center. http://chl.erdc.usace.army.mil/chetn (accessed January 2009).

Northcutt, P. and McFalls, J., 1998. Performance testing of erosion control products: what have we learned after five complete evaluation cycles. Proceedings of the 
International Erosion Control Association Conference, 29, 199-218.

Oumeraci, H.; D’Eliso, C., and Kortenhaus, A., 2005. Breaching of coastal dikes: State of the art and study plan overview. FLOOD site Project Report, Progress report Nr. 1, LWI report Nr. 910. http://www.floodsite.net/html/partner_area/search_ results3b.asp?docID=136.

Pan, Y.; Li, L.; Amini, F., and Kuang, C. P., 2013. Full scale HPTRM strengthened levee testing under combined wave and surge overtopping conditions: Overtopping hydraulics, shear stress and erosion analysis, Journal of Coastal Research, 29(1), 182-200.

Piontkowitz, T., 2009. Failure of Grass Cover Layers at Seaward and Shoreward Dike Slopes, Design, Construction \& Performance. Danish Coastal Inspectorate, 2009. 12. www.masterpiece.dk/UploadetFiles/10852/25/EroGrass_report_A_final.pdf.

Powledge, G.R.; Ralston, D.C.; Miller, P.; Chen, Y.H.; Clopper, P.E., and Temple, D.M., 1989. Mechanics of overflow erosion on embankments. II: Hydraulic and design considerations. Journal of Hydraulic Engineering, 115(8), 1056-1075.

Ralston, D.C., 1987. Mechanics of Embankment Erosion During Overflow. Hydraulic Engineering, Proceedings of the 1987 ASCE National Conference on Hydraulic Engineering (Williamsburg, Virginia), pp. 733-738.

Sills, G.L.; Vroman, N.D.; Wahl, R.E., and Schwanz, N.T., 2008. Overview of New Orleans levee failures: lessons learned and their impact on national levee design and assessment. Journal of Geotechnical and Geoenvironmental Engineering, 134(5), $556-565$.

Singh, V.P., 1996. Dam breach modeling technology. Kluwer Academic Publisher.

Singh, K.P. and Snorrason, A., 1982. Sensitivity of Outflow Peaks and Flood Stages to the Selection of Dam Breach Parameters and Simulation Models. SWS Contract Report 288, Illinois Department of Energy and Natural Resources, State Water Survey Division, Surface Water Section at the University of Illinois, 179 p. 
Sprague, C. J., 1999. Green Engineering: Optimizing Erosion Control with Vegetation and RECPs, Part one. CE NEWS, February, 1999 pp. 54-61.

Sturm, T.W., 2001. Open Channel Hydraulics. New York: McGraw-Hill.

van der Meer, J.W.; Schrijver, R.; Hardeman, B.; van Hoven, A.; Verheij, H., and Steendam, G.J., 2009. Guidance on erosion resistance of inner slopes of dikes from three years of testing with the wave overtopping simulator. In: Proceedings of the ICE: Coasts, Marine Structures and Breakwaters (Edinburgh, United Kingdom), pp. 460-473.

Yuan, S.Y.; Li, L., Amini, F., and Tang, H.W., 2014. Turbulence measurement of combined wave and surge overtopping over a full scale HPTRM strengthened levee. Journal of Waterways, Coastal and Ocean Engineering, 140(4), 04014014.

Zech, Y. and Soares-Frazão, S., 2007. Dam-break flow experiments and real-case data. A database from the European IMPACT research. Journal of Hydraulic Research, $45(\mathrm{SI}), 5-7$. 


\section{List of Figures}

Fig. 1. Vegetated HPTRM system: (a) vegetated HPTRM system, (b) HPTRM mat, and (c) structure illustration.

Fig. 2. Combined wave and surge overtopping scenario for earthen levees strengthened with HPTRM system on crest and landward-side slope. Freeboard $R_{c}$ is defined as vertical distance between the still water elevation and crest elevation, SWL is sea water level, $H_{m 0}$ is significant wave height, $m$ is water-side slope.

Fig. 3. Profile view of the large wave flume and location of levee embankment.

Fig. 4. Locations of sampling points on crest and landward-side slope.

Fig. 5. EFA (erosion function apparatus) adapted from Briaud et al. (2001): (a) conceptual diagram; (b) photograph of test section.

Fig. 6. EFA test results plotted in the erodibility classification charts of velocities (a) and shear stresses (b) (the erodibility classification charts are from Briaud et al., 2008).

Fig. 7. Total erosion depths measured after combined wave and surge overtopping tests.

Fig. 8. Erosion rate versus average shear stress (a) and versus average flow velocity (b) at the monitoring points.

Fig. 9. Erosion rate versus velocity for EFA tests and flume tests: (a) plotted in the range of EFA test results, (b) plotted in the range of full-scale flume test results. 
Fig. 10. Samples of grass cover in poor condition (A1) and good condition (A4).

Fig. 11. The top layer of the vegetated HPTRM system is protected by the grass rather than the vegetated HPTRM system.

Fig. 12. Two types of erosion mechanisms of soil loss from levee surface: (a) particle erosion, (b) block erosion.

Fig. 13. Failure modes of HPTRM-strengthened levee: (a) torn off of the HPTRM mat, (b) the erosion develops to the bottom of the HPTRM mat, (c) torn off of the HPTRM mat in the process of the development of the particle erosion.

1. The erosion characteristics of the vegetated HPTRM system, including the distribution of erosion and the key hydraulic parameters is investigated.

2. The characteristics of the erosion rates of naked clay, grass lining and vegetated HPTRM system is investigated.

3. A conceptual model of the erosion of landward-side slope is presented. 


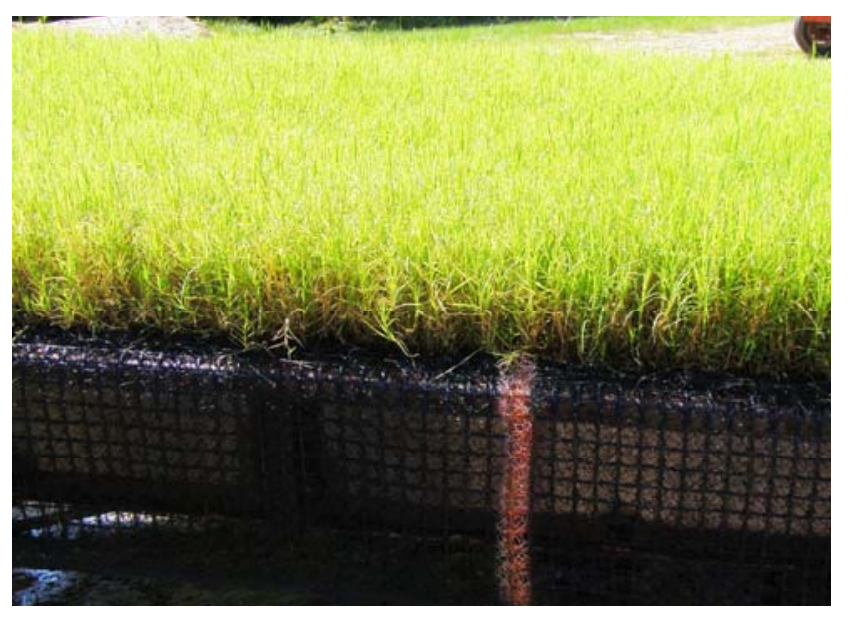

(a) Vegetated HPTRM system

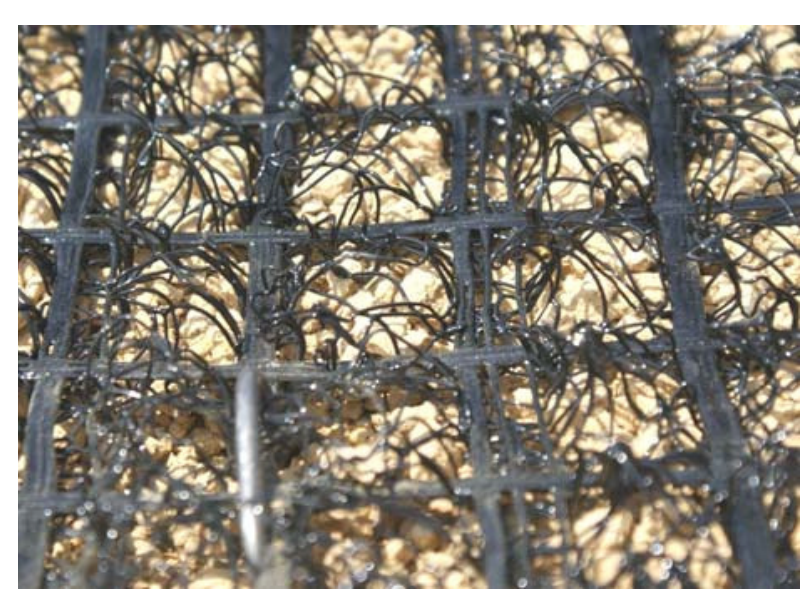

(b) HPTRM mat

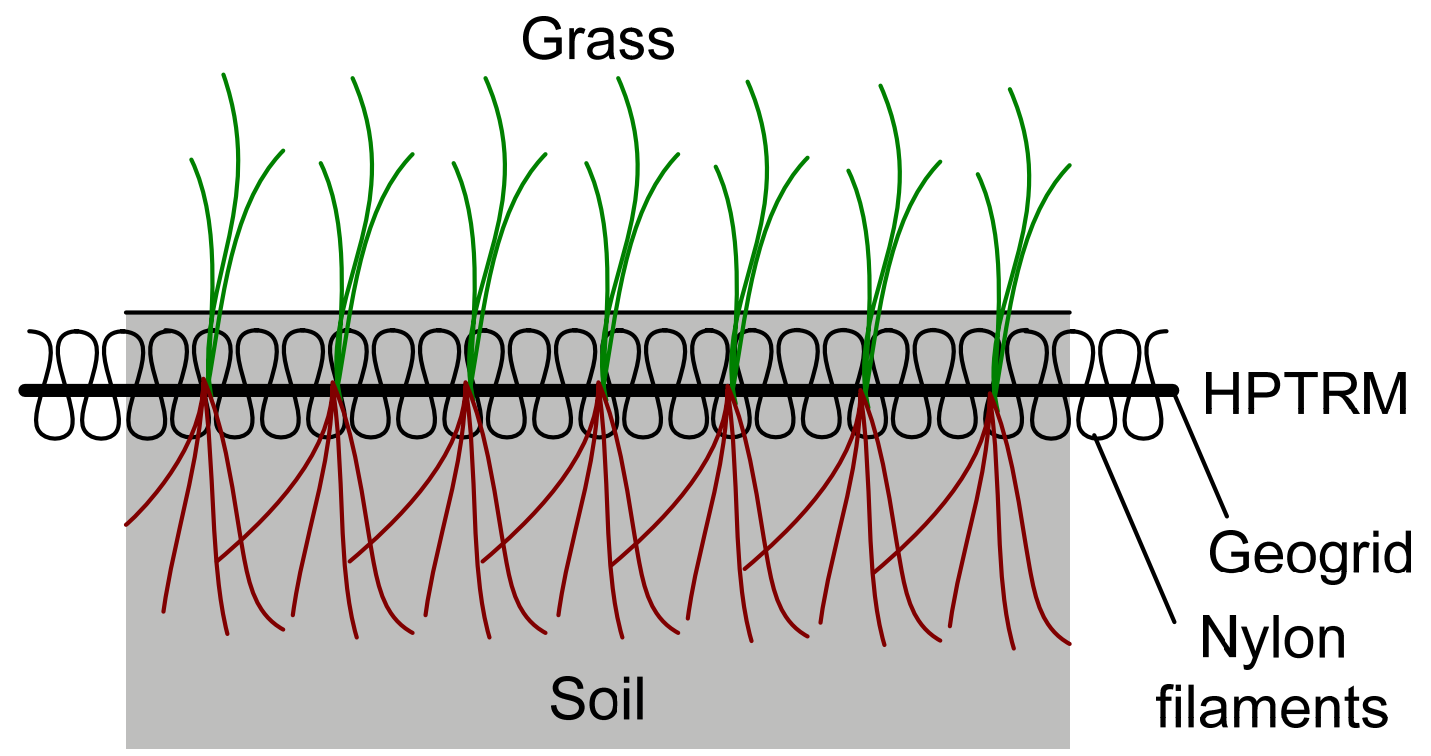

(c) Structure illustration 


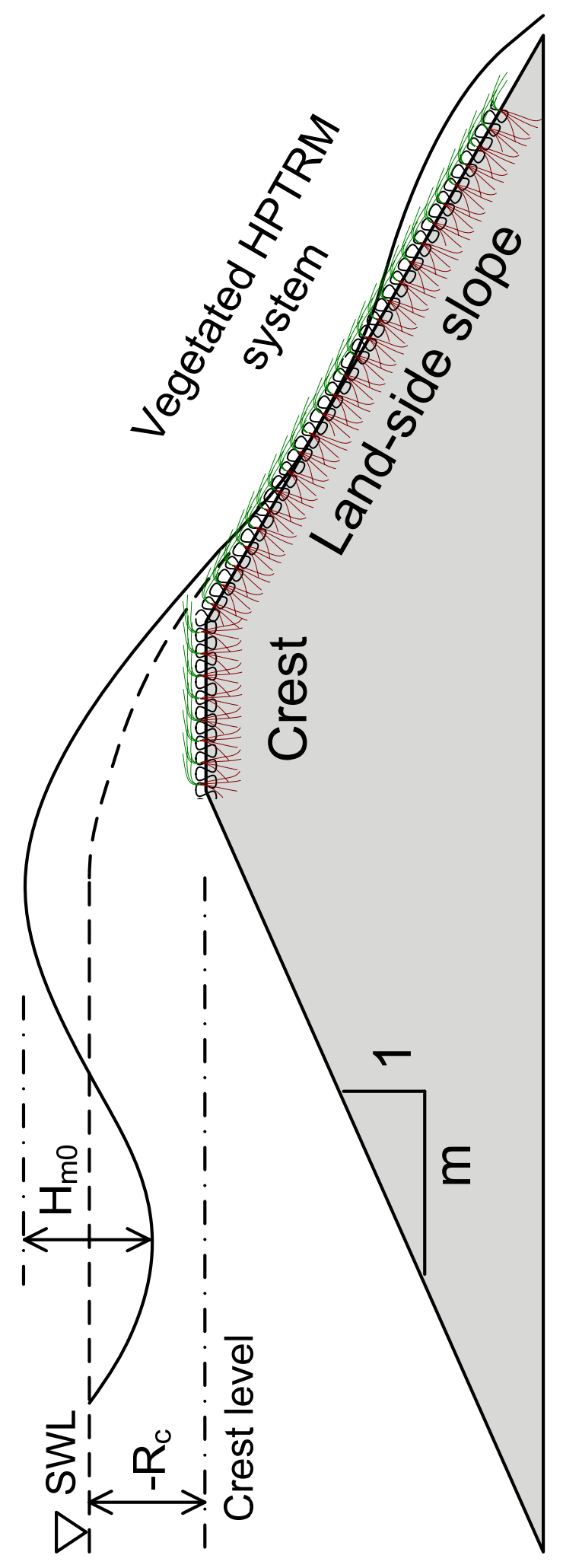

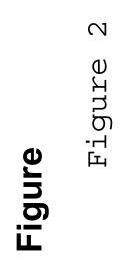




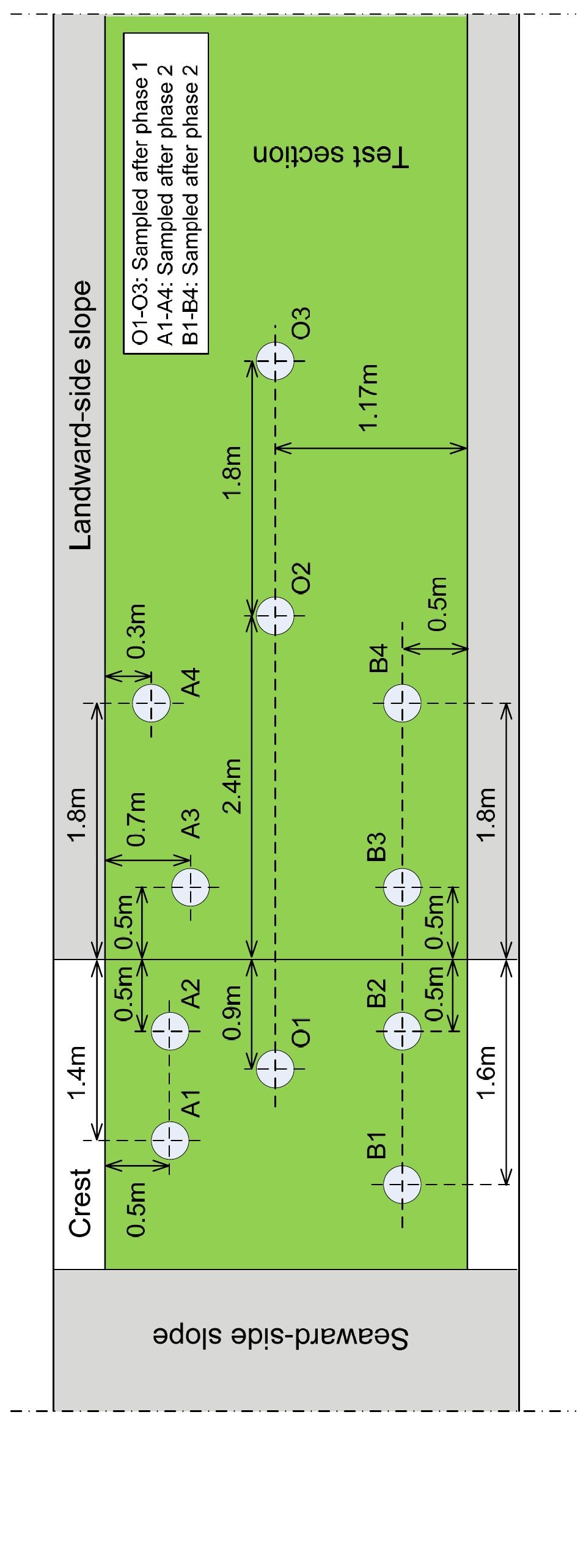



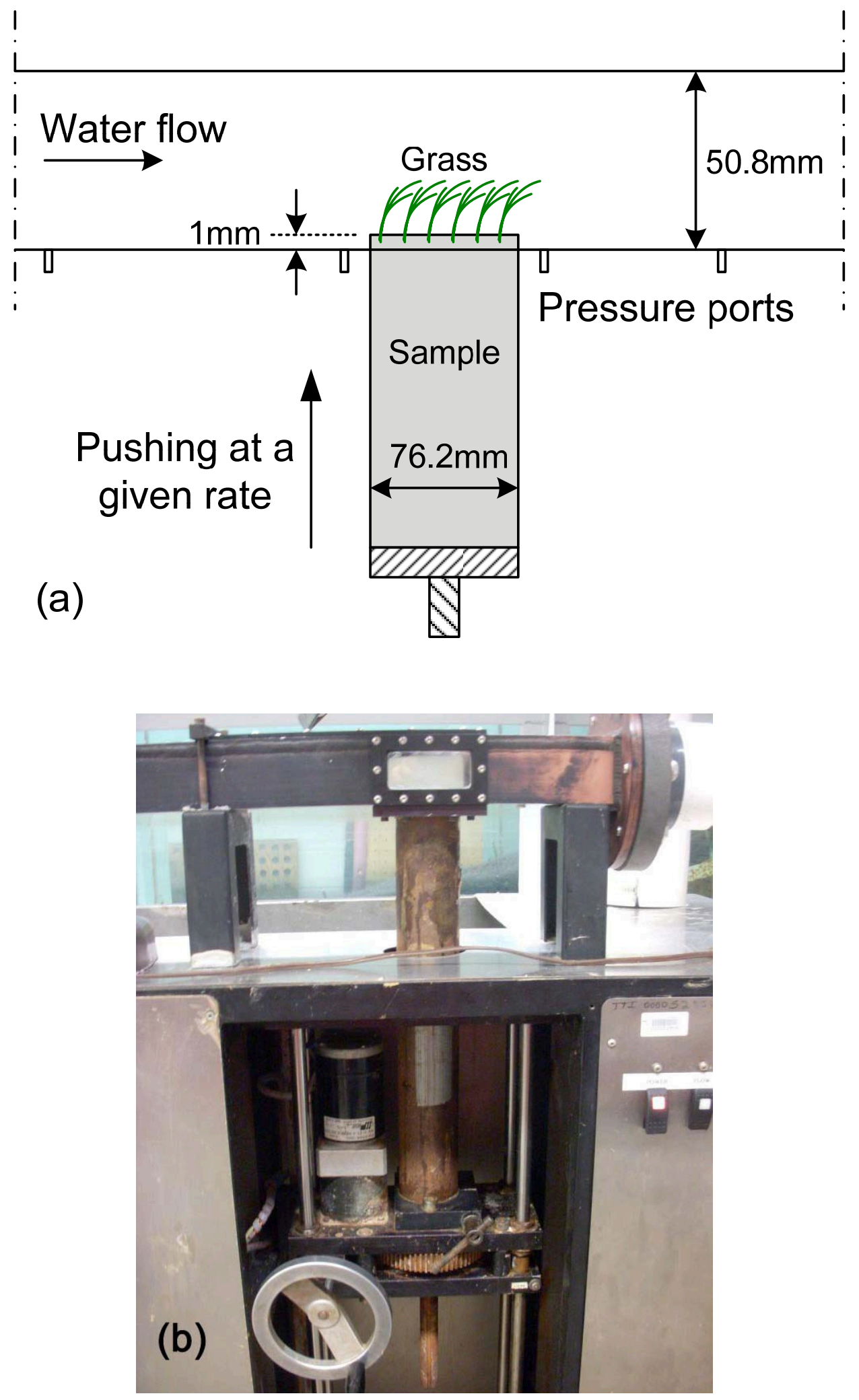


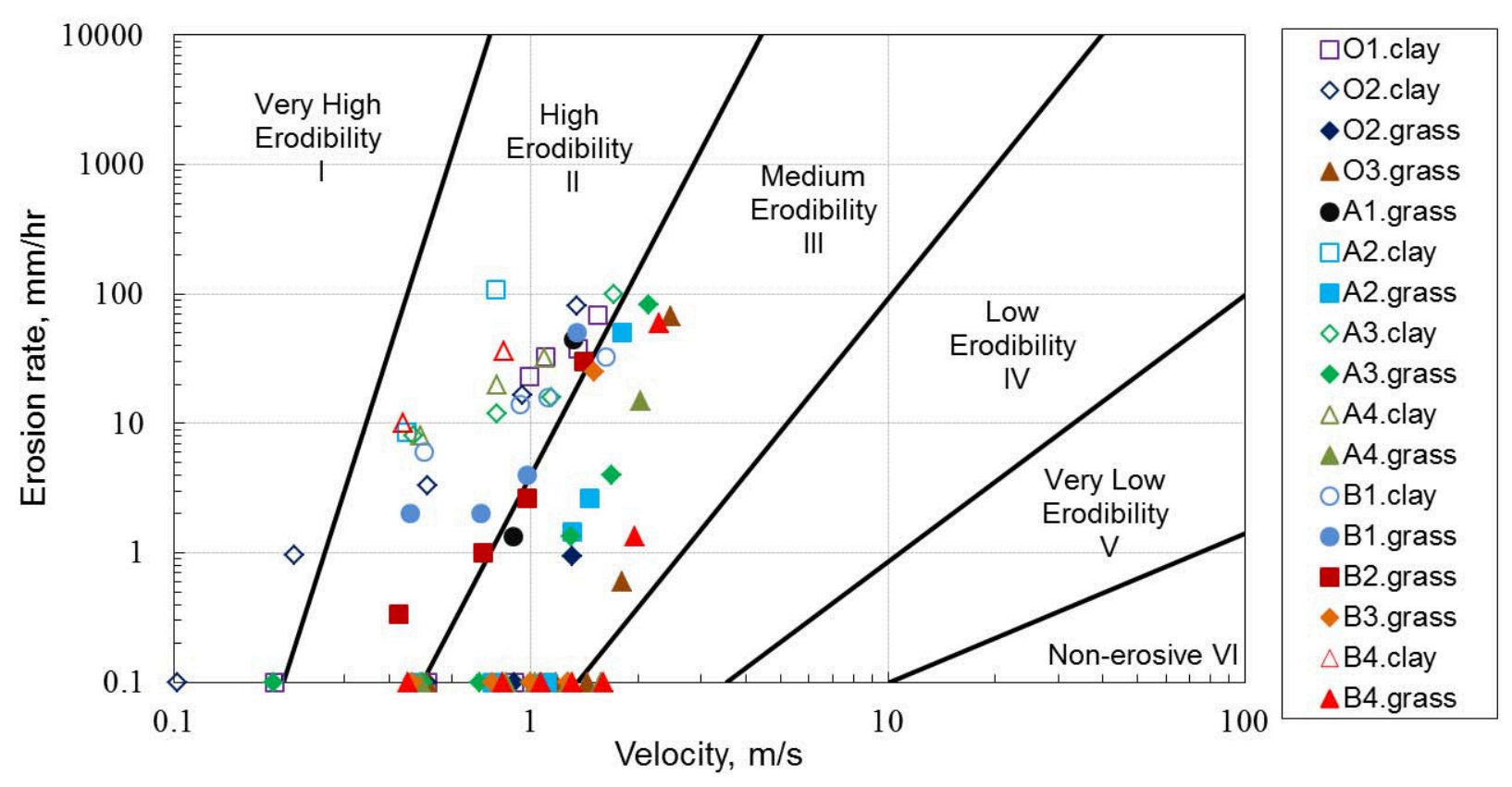

(a) Erodibility classification chart of velocities

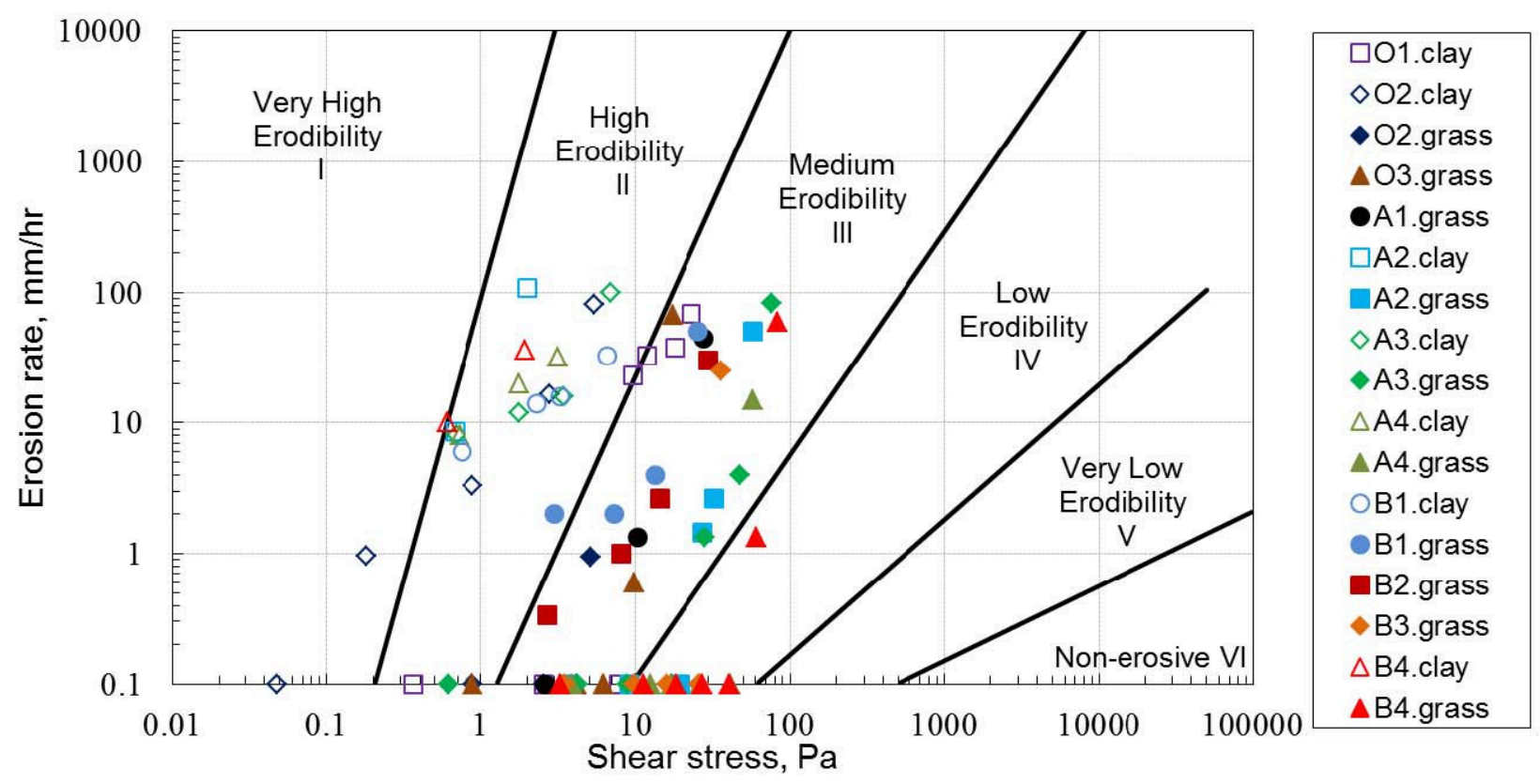

(b) Erodibility classification chart of shear stresses 


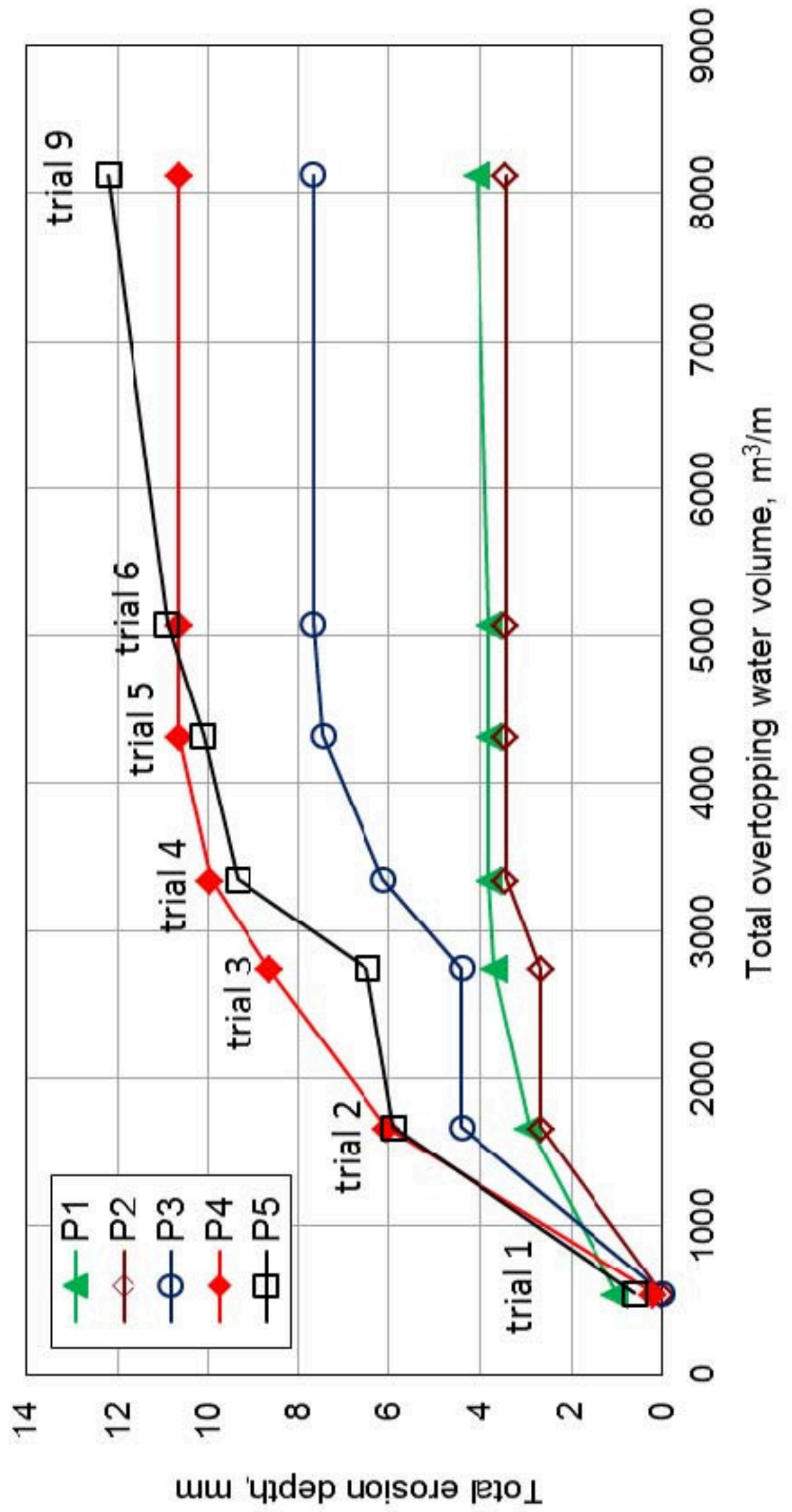




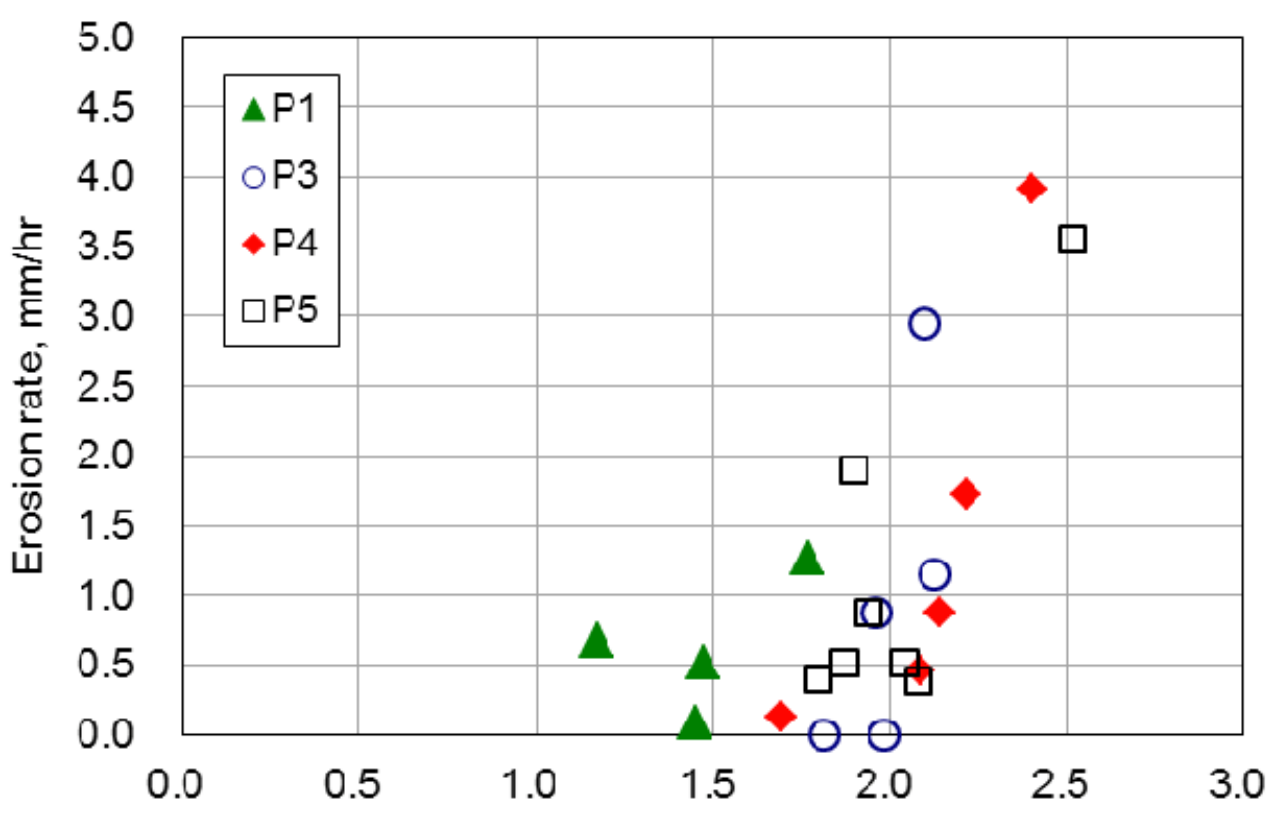

Flow velocity, $\mathrm{m} / \mathrm{s}$

(a) Erosion rate versus average shear stress

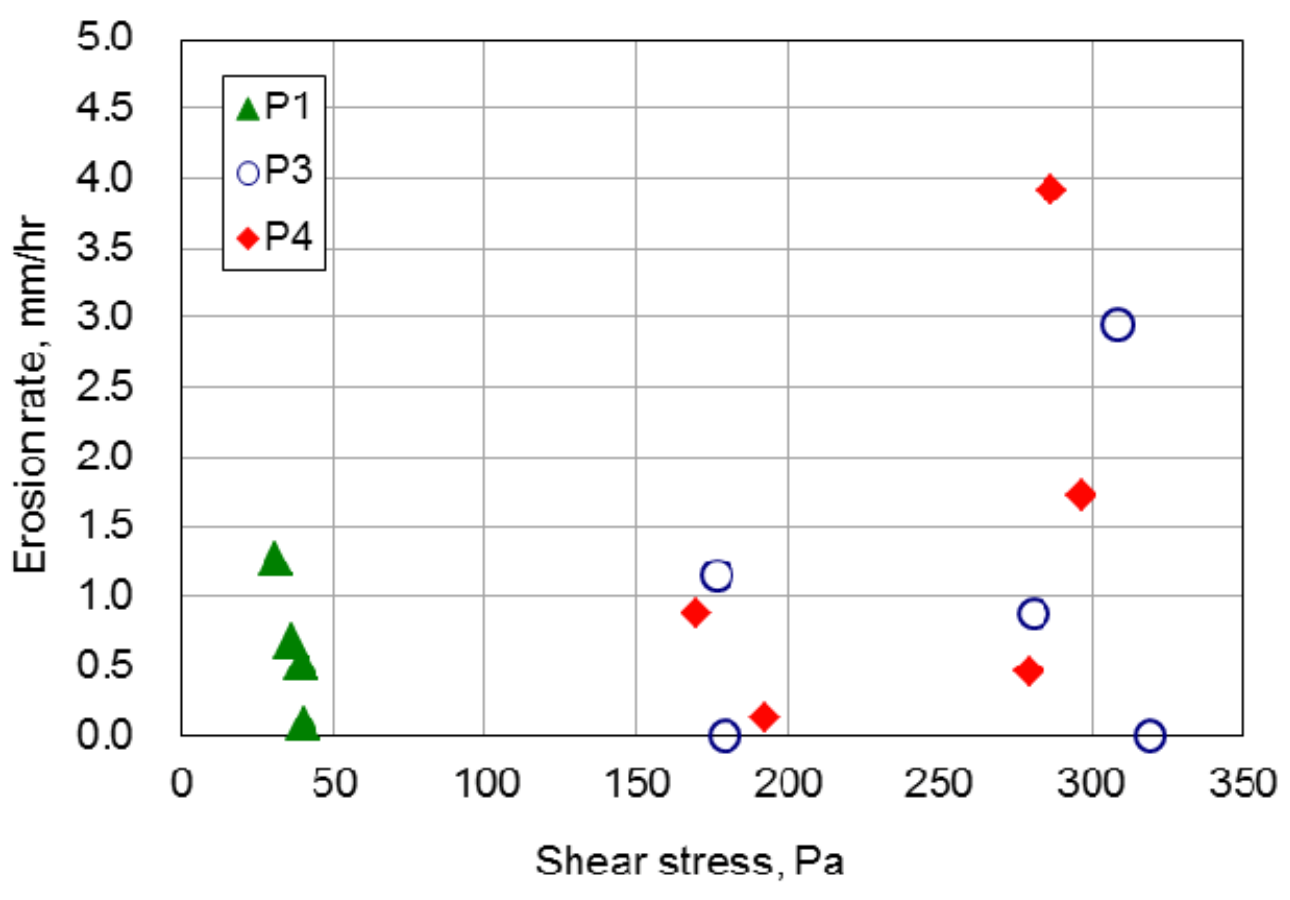

(b) Erosion rate versus average flow velocity 

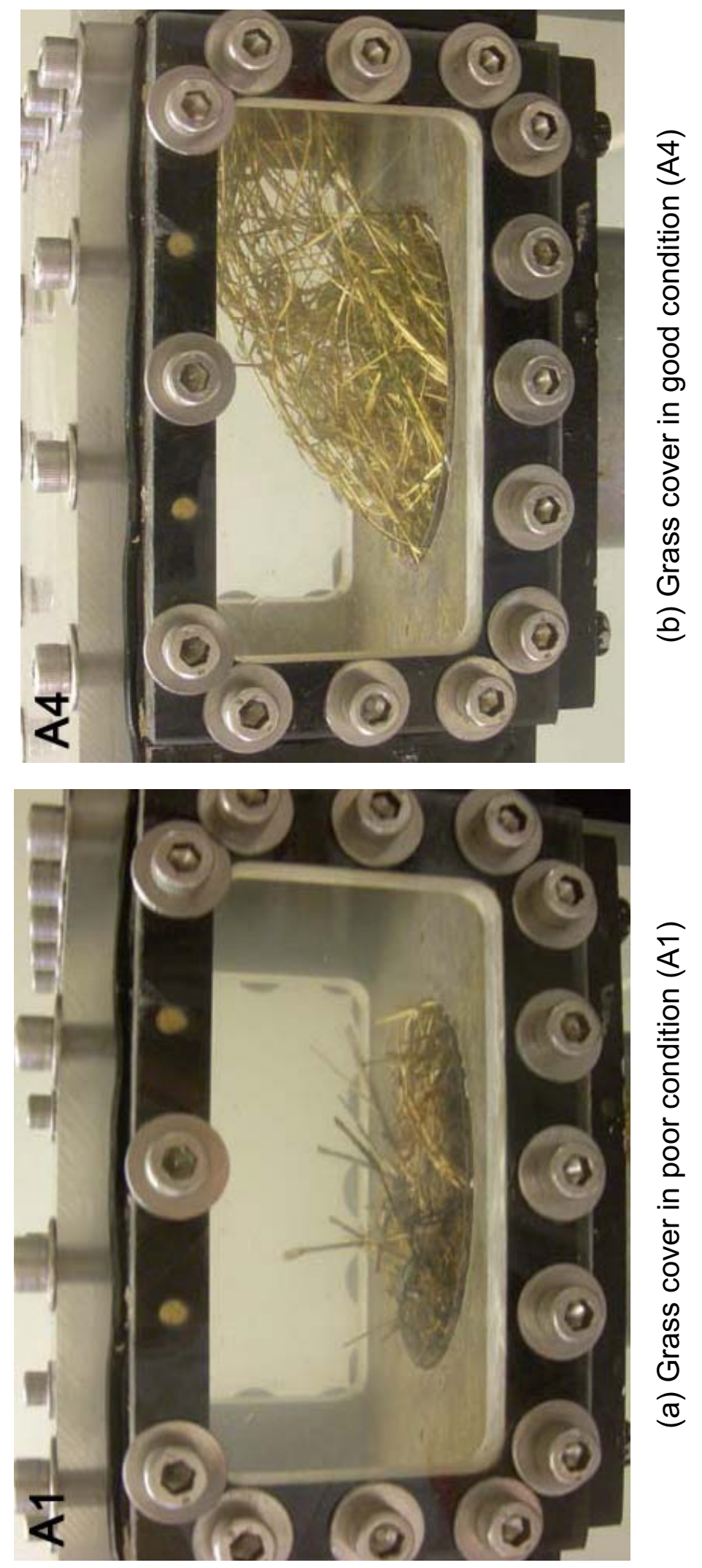


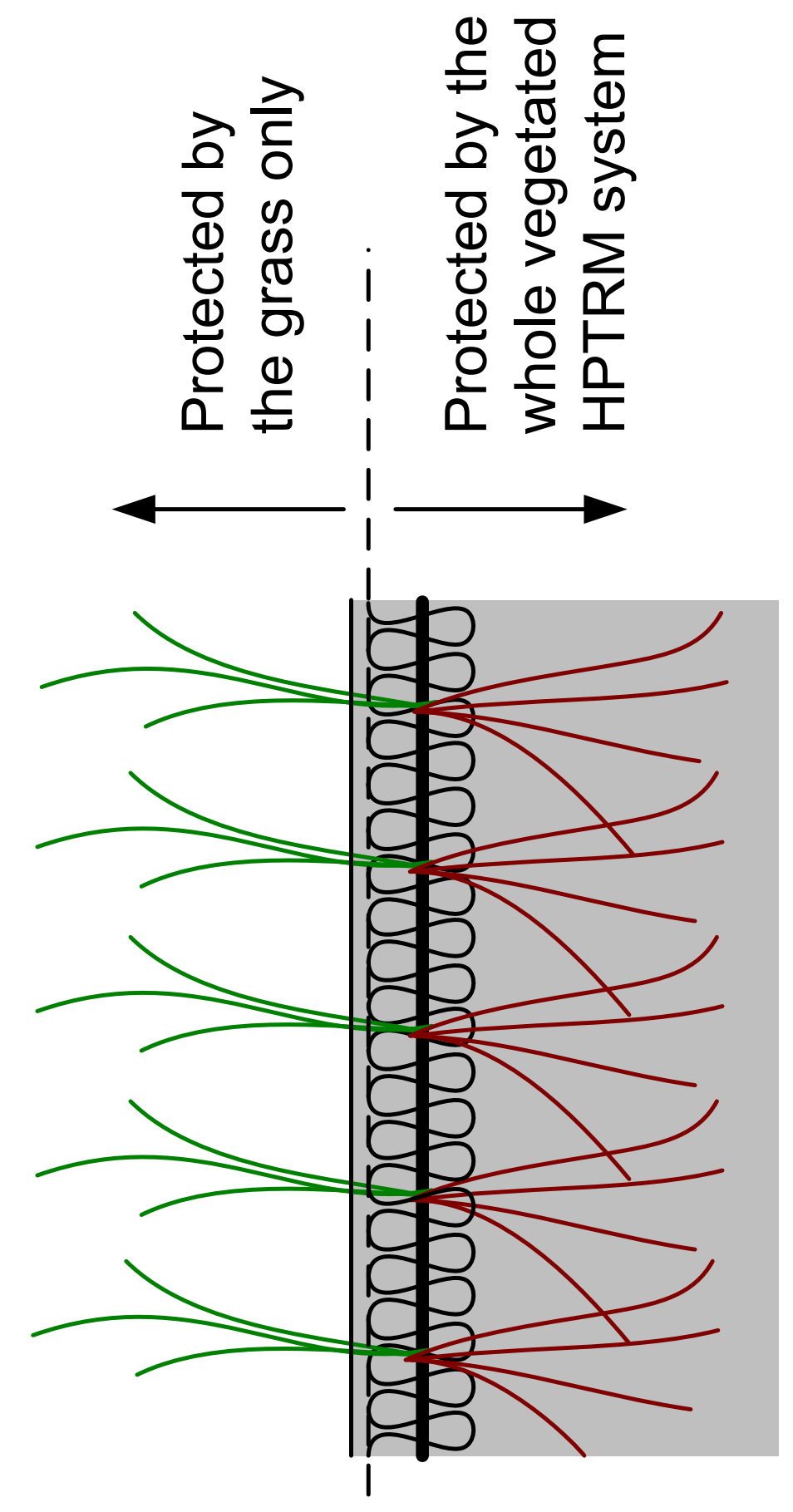




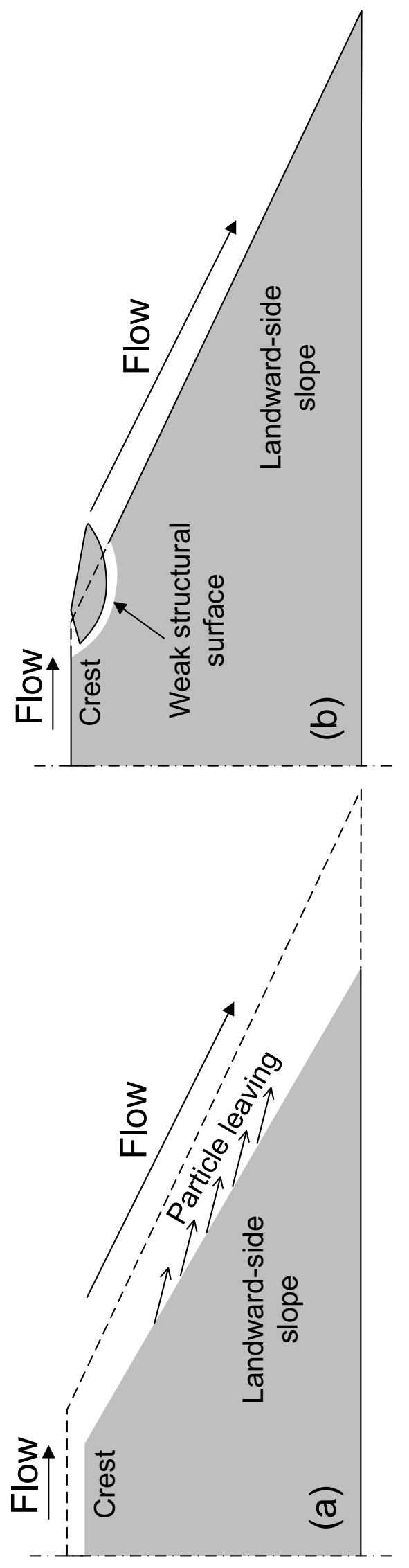




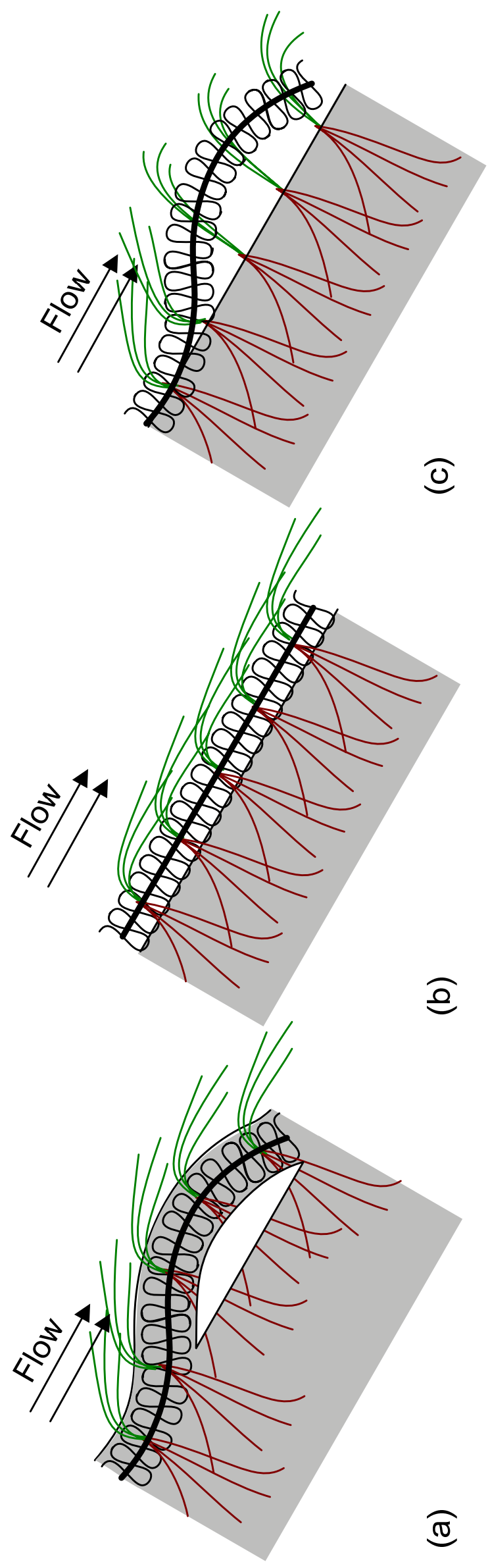

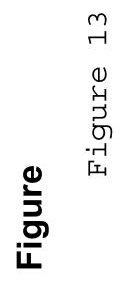

